\title{
Effects of Moisture Content and Plasticity Index on Duncan-Chang Model Parameters of Hydraulic Fill Soft Soil
}

\author{
Erzhong Chen, Meng Yan, Jihui Ding, Cen Gao, Yu Gan \\ Institute of Civil Engineering, University of Hebei, Baoding, China \\ Email: 1245598736@qq.com
}

How to cite this paper: Chen, E.Z., Yan, M., Ding, J.H., Gao, C. and Gan, Y. (2019) Effects of Moisture Content and Plasticity Index on Duncan-Chang Model Parameters of Hydraulic Fill Soft Soil. World Journal of Engineering and Technology, 7, 408-417. https://doi.org/10.4236/wjet.2019.73030

Received: June 26, 2019

Accepted: August 4, 2019

Published: August 7, 2019

Copyright $\odot 2019$ by author(s) and Scientific Research Publishing Inc. This work is licensed under the Creative Commons Attribution International License (CC BY 4.0).

http://creativecommons.org/licenses/by/4.0/

(c) (i) Open Access

\begin{abstract}
In order to explore the effects of moisture content and plasticity index on Duncan-Chang model parameters $K, n, C$ and $R_{f}$ we selected 8 groups of soft soil with water content of $69.1 \%-94.3 \%$ and plasticity index of $32.2-54.1$ for triaxial unconsolidated undrained shear test. The results show that $C_{u u}, K$ and $n$ values all showed a downward trend, and $R_{f}$ variation was not obvious with the increase of moisture content. The variation rule of each parameter is not obvious with the increase of plasticity index. When moisture content is constant, $C_{u u}$ and $n$ values do not change much, $K$ increases with the increase of plasticity index within the range of $70 \%-80 \%$ moisture content, and does not change much with the increase of plasticity index when moisture content is greater than $80 \%, R_{f}$ has no obvious rule. When the plasticity index is constant, $C_{u u}, K$ and $n$ decrease with the increase of moisture content, $R_{f}$ has no obvious rule. The maximum value of $C_{u l}$ is $20.18 \mathrm{kPa}$, the minimum is 3.72 $\mathrm{kPa}$, and the maximum to minimum ratio is 5.42. The maximum value of $K$ is 0.517 , the minimum is 0.022 , and the maximum to minimum ratio is 23.5 . The maximum value of $n$ is 1.198 , the minimum is 0.150 , and the maximum to minimum ratio is 7.99 . The maximum value of $R_{f}$ is 0.872 , the minimum is 0.679 , and the maximum to minimum ratio is 1.28 .
\end{abstract}

\section{Keywords}

Moisture Content, Plasticity Index, Duncan-Chang Model, Unconsolidated Undrained Test

\section{Introduction}

The constitutive relation of soil is the rule to reveal the internal mechanical 
properties of soil. In recent years, soft soil foundation has been paid more and more attention. Especially in the coastal areas, the hydraulic filling of soft foundation is more and more widely distributed. Compared with other general soft soil and clay, hydraulic fill soft soil is a kind of artificial soft soil, characterized by high moisture content and low strength. After it is used as foundation, it will often lead to the destruction of buildings due to the excessive settlement and insufficient bearing capacity in the later stage. Therefore, it is very important to study the stress-strain relation, or constitutive relation, of soft soil.

Duncan-Chang model is a nonlinear elastic model of soil, with simple parameters and clear concept, which can be obtained by conventional triaxial shear test, and can well reflect the stress-strain law of soil. Many scholars have studied the effects of basic physical indexes on the parameters of Duncan-Chang model. Liu Xiaowen et al. [1] studied the stress-strain curves and other mechanical properties of laterite with different compactness, and obtained the Duncan-Chang model parameters. Chen Wei et al. [2] studied the stress-strain curves and other mechanical properties of compacted loess under different basic indexes through triaxial test, and obtained the Duncan-Chang model parameters. Liao Hongjian et al. [3] obtained the stress-strain curves of remolded saturated loess through triaxial test and analyzed the influencing factors of Duncan-Chang model parameters. Wu Nengsen et al. [4] studied the influence of moisture content on Duncan-Chang model parameters of granite residual soil. Yang Xuehui [5] studied the Duncan-Chang model of unsaturated remolded loess under different conditions, and gave the intensity index of unsaturated remolded loess and the change rule of Duncan-Chang model parameters with the initial conditions. Zdravkovic and Jardin [6] discussed the anisotropy of the rotation of the middle principal stress direction caused by consolidation, and pointed out that it had obvious influence on the strength and deformation of soil, and then affected the parameters of Duncan-Chang model. Cokca et al. [7] studied the effects of moisture content on the cohesion and internal friction angle of Duncan-Chang model of unsaturated clay. Cheng Ying et al. [8] analyzed the triaxial test results of marine and fluvial soft soils by using Duncan-Chang model, and gave the change rules of model parameters and dry density. Based on the triaxial test results, Wang Shuai [9] established Duncan-Chang model of coastal soft soil with different initial degree of consolidation.

It can be seen from the above results that there are few studies on the influence of moisture content and plasticity index on Duncan-Chang model parameters of soft soil. Therefore, this experiment mainly studies the influence of moisture content and plasticity index on the parameters of Duncan-Chang model.

Firstly, the basic physical indexes of selected soil samples were determined. Then, Duncan-Chang model parameters were obtained by triaxial unconsolidated and undrained test. Finally, the relationship between water content and plastic limit on Duncan-Chang model parameters was analyzed. 


\section{Project Profile}

The test soil samples were taken from a blow fill site located in tidal flats and shallow sea areas. The landform is mainly alluvial plain, and the landform unit is delta, which belongs to the tidal landform type of estuary, sand mouth and sand island. The main strata from top to bottom include: backfill sand, silt (blowing), coarse sand (blowing), fine sand (blowing), silt-silt soil (blowing), clay-silty clay, silt soil-clay. The sampling area is mainly located in the silt distribution area, and the sampling depth is 5 - $15 \mathrm{~m}$ below the surface. Related physical indicators are shown in Table 1.

Plasticity is the characteristic of clay, which reflects the degree of interaction between clay and water. Figure 1 shows the plasticity diagram of the test soil sample. As can be seen from Figure 1, the soil samples are near line A, and all

Table 1. Physical and mechanical properties of soil samples.

\begin{tabular}{ccccccccc}
\hline Test group & Moisture content \% & Density $\mathrm{g} / \mathrm{cm}^{3}$ & Saturation \% & Void ratio & Liquid limit \% & Plastic limit \% & Plastic index & Liquidity index \\
\hline 1 & 69.1 & 1.54 & 95.5 & 1.93 & 78.4 & 40.4 & 38.0 & 0.76 \\
2 & 74.2 & 1.58 & 100.0 & 1.96 & 79.8 & 28.0 & 51.8 & 0.89 \\
3 & 79.8 & 1.50 & 96.8 & 2.20 & 85.5 & 31.4 & 54.1 & 0.89 \\
4 & 84.9 & 1.51 & 100.0 & 2.26 & 87.2 & 33.6 & 53.6 & 0.96 \\
5 & 94.3 & 1.42 & 94.9 & 2.65 & 100.0 & 48.3 & 51.7 & 0.89 \\
6 & 83.8 & 1.50 & 98.5 & 2.27 & 89.4 & 44.0 & 45.4 & 0.88 \\
7 & 76.2 & 1.56 & 100.0 & 2.03 & 75.5 & 43.3 & 32.2 & 1.02 \\
8 & 76.8 & 1.53 & 98.2 & 2.10 & 79.8 & 34.7 & 45.1 & 0.93 \\
Range & $69.1-94.3$ & $1.42-1.58$ & $94.9-100.0$ & $1.93-2.65$ & $75.5-100.0$ & $28.0-48.3$ & $32.2-54.1$ & $0.76-1.02$ \\
Average & 79.89 & 1.52 & 97.99 & 2.18 & 84.45 & 37.96 & 46.49 & 0.90 \\
\hline
\end{tabular}

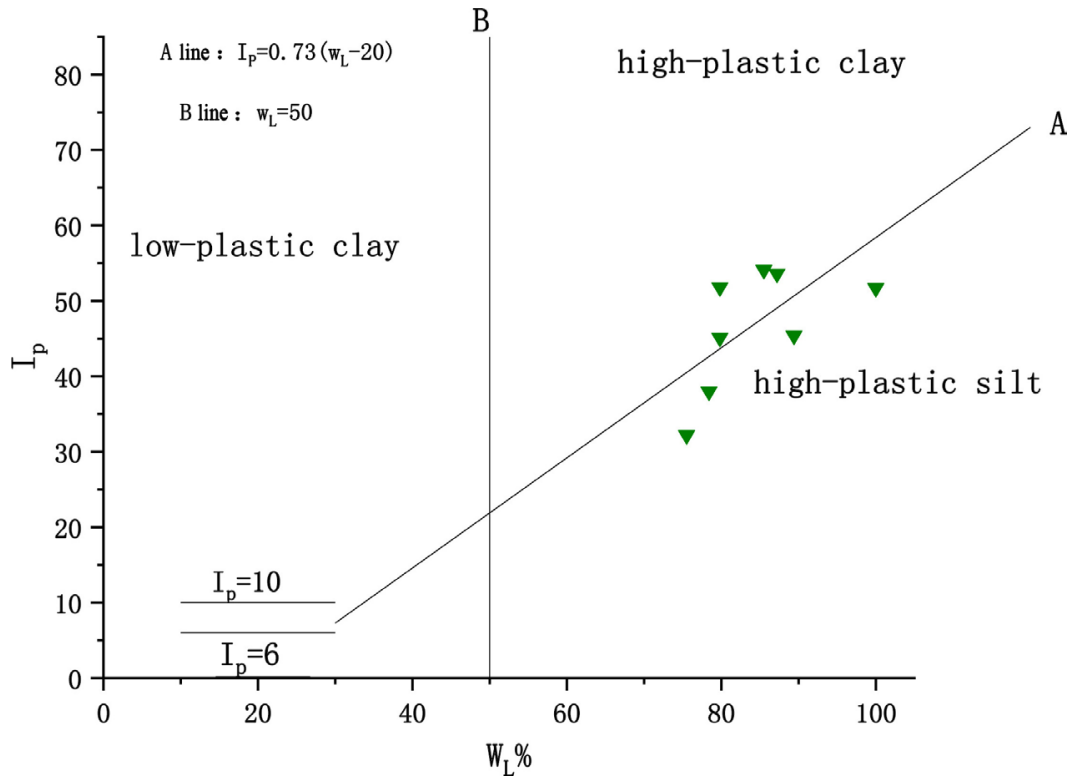

Figure 1. Distribution diagram of soil moisture content and plasticity index. 
are high-plastic soils.

\section{Introduction to Duncan-Chang Model}

Kondner pointed out in 1963 that the stress-strain curve of soil triaxial test can be fitted by hyperbola:

$$
\sigma_{1}-\sigma_{3}=\frac{\varepsilon_{1}}{a+b \varepsilon_{1}}
$$

where: $\left(\sigma_{1}-\sigma_{3}\right)$ is deviator stress. $\varepsilon_{1}$ is the axial strain. $a, b$ are the test constant, and $a$ is the inverse of the initial tangent deformation modulus $E_{i} . b$ is the inverse of the limiting deviant stress $\left(\sigma_{1}-\sigma_{3}\right)_{u}$. Among them:

$$
\begin{gathered}
E_{i}=K P_{a}\left(\frac{\sigma_{3}}{P_{a}}\right)^{n} \\
\left(\sigma_{1}-\sigma_{3}\right)_{u}=\frac{2 c \cos \varphi+2 \sigma_{3} \sin \varphi}{R_{f}(1-\sin \varphi)} \\
R_{f}=\frac{\left(\sigma_{1}-\sigma_{3}\right)_{f}}{\left(\sigma_{1}-\sigma_{3}\right)_{u}}
\end{gathered}
$$

where: $P_{a}$ is atmospheric pressure, with $P_{a}$ value of $101.4 \mathrm{kPa}$, and the dimension is the same as $\sigma_{3} ; R_{f}$ is the damage ratio; $c, \varphi$ is the cohesion and internal friction Angle of the soil sample; $K, n$ are the test constant; $\left(\sigma_{1}-\sigma_{3}\right)_{f}$ is the strength of the soil.

According to Equations (1)-(3), the tangent deformation modulus of Duncan-Chang model can be expressed as:

$$
E_{t}=K P_{a}\left(\frac{\sigma_{3}}{P_{a}}\right)^{n}\left[1-R_{f} \frac{(1-\sin \varphi)\left(\sigma_{1}-\sigma_{3}\right)}{2 c \cos \varphi+2 \sigma_{3} \sin \varphi}\right]^{2}
$$

This experiment mainly studies five parameters of Duncan-Chang model: $K, n, c, \varphi$ and $R_{f}$.

\section{Test Results and Analysis}

The effects of moisture content and plasticity index on the parameters of Duncan-Chang model was studied by triaxial unconsolidated undrained shear test. The model parameters of the whole group are obtained by taking the experimental data of the third group of soil samples as an example. The relationship between deviator stress difference and axial strain of soil samples in group 3 is shown in Figure 2.

\section{1. $C_{u и}, \varphi_{u и}$}

$C_{u u}, \varphi_{u u}$ are generally obtained by drawing Mohr circle of stress under different confining pressures. As the soil sample is nearly saturated and does not drain during the shear process, the force between shear planes is assumed by the excess pore water pressure, and the friction between the soil particles does not 
exist, so $\varphi_{u и}=0$. See Table 2 for details.

\section{2. $\boldsymbol{R}_{f}$}

$R_{f}$ is obtained by drawing $\varepsilon_{1} /\left(\sigma_{1}-\sigma_{3}\right) \sim \varepsilon_{1}$ relation curves under different confining pressures, as shown in Figure 3. $\varepsilon_{1} /\left(\sigma_{1}-\sigma_{3}\right) \sim \varepsilon_{1}$ curves are fitted to obtain intercept $a$ and slope $b$. Combining Equations (3) and (4), $E_{i}$ and $R_{f}$ are further obtained. $R_{f}$ is averaged, as shown in Table 2.

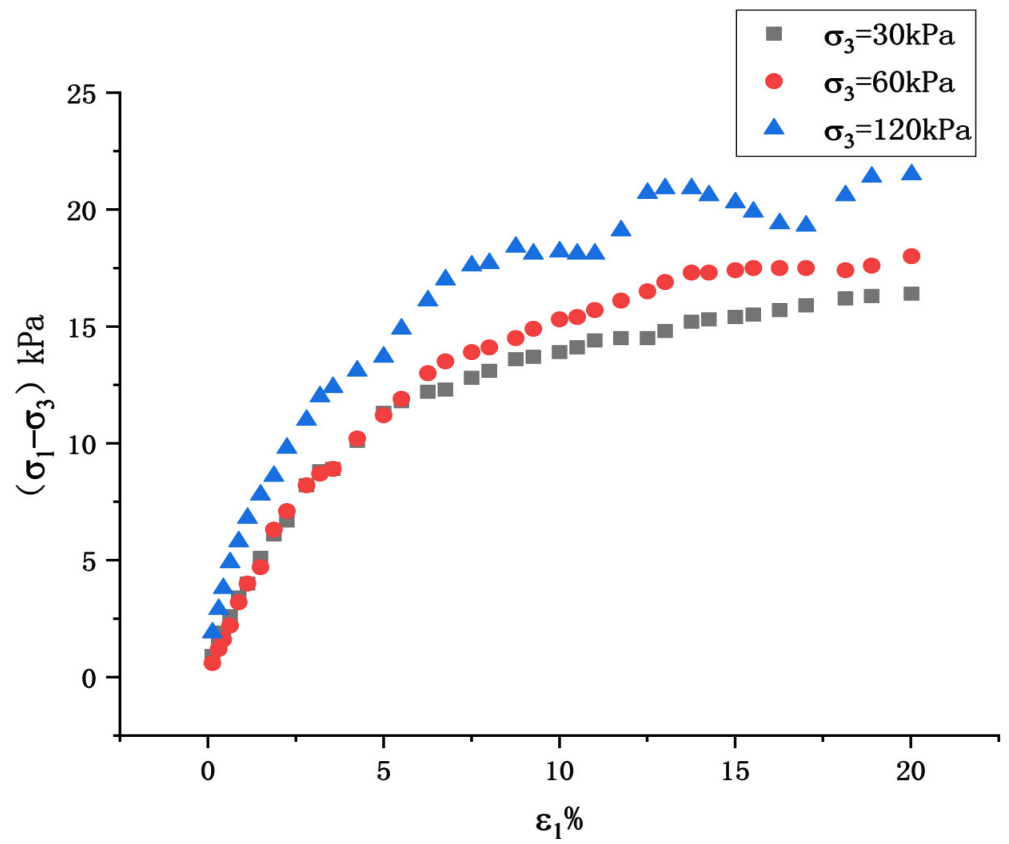

Figure 2. $\left(\sigma_{1}-\sigma_{3}\right) \sim \varepsilon_{1}$ relation curve.

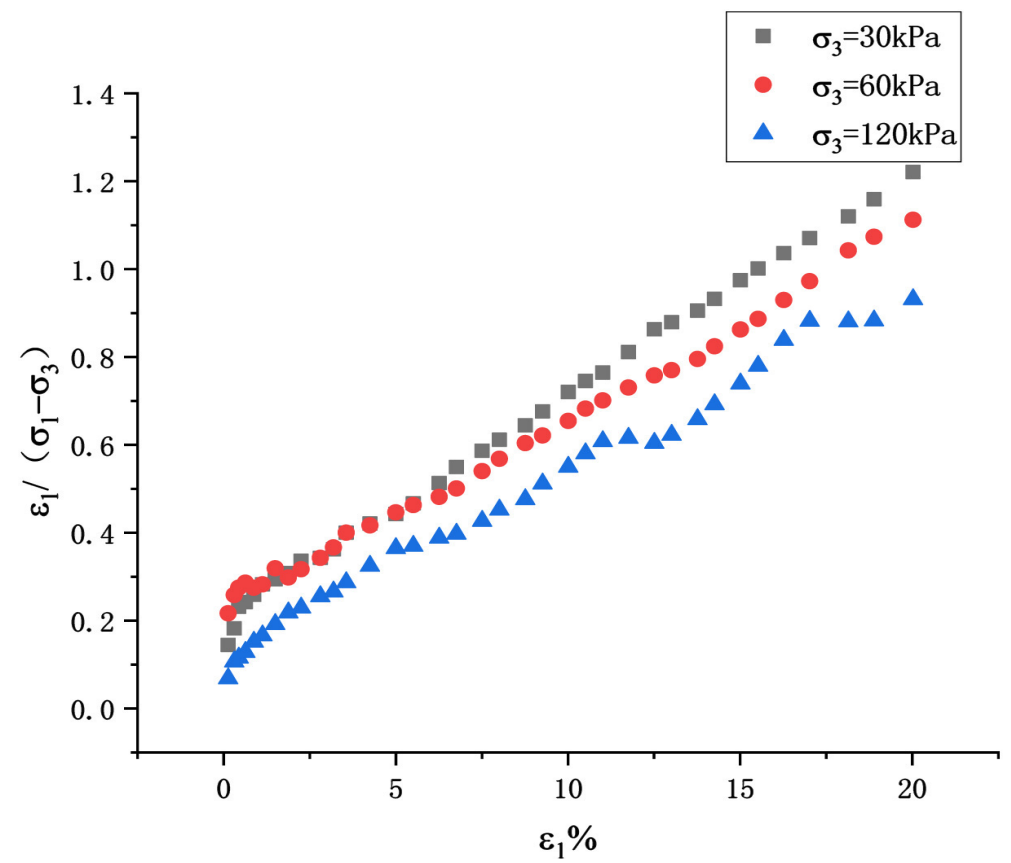

Figure 3. $\varepsilon_{1} /\left(\sigma_{1}-\sigma_{3}\right) \sim \varepsilon_{1}$ relation curve. 


\section{3. $K, n$}

$K, n$ through mapping the $\lg \left(\sigma_{3} / P_{a}\right) \sim \lg \left(E_{i} / P_{a}\right)$ curve to obtain, as shown in Figure 4.

It can be seen from Table 2 that parameters $C_{u l,} K$ and $n$ of Duncan-Chang model of soft soil fill have a large variation range, while $R_{f}$ has a small variation range. The average value of $R_{f}$ is 0.773 , and the coefficient of variation is 0.08 . From Figures 5-7, it can be seen that $C_{u u,} K$ and $n$ basically show a downward trend with the increase of moisture content, and there is no obvious rule with the change of plasticity index.

Figures 8-10 are the cloud diagram of Duncan-Chang model parameters $C_{u u}$ $K$ and $n$ changing with water content and plasticity index. Figure 8 shows that when the moisture content is constant, the $C_{u u}$ does not change much. When the plasticity index is constant, $C_{u l}$ decreases with the increase of moisture content.

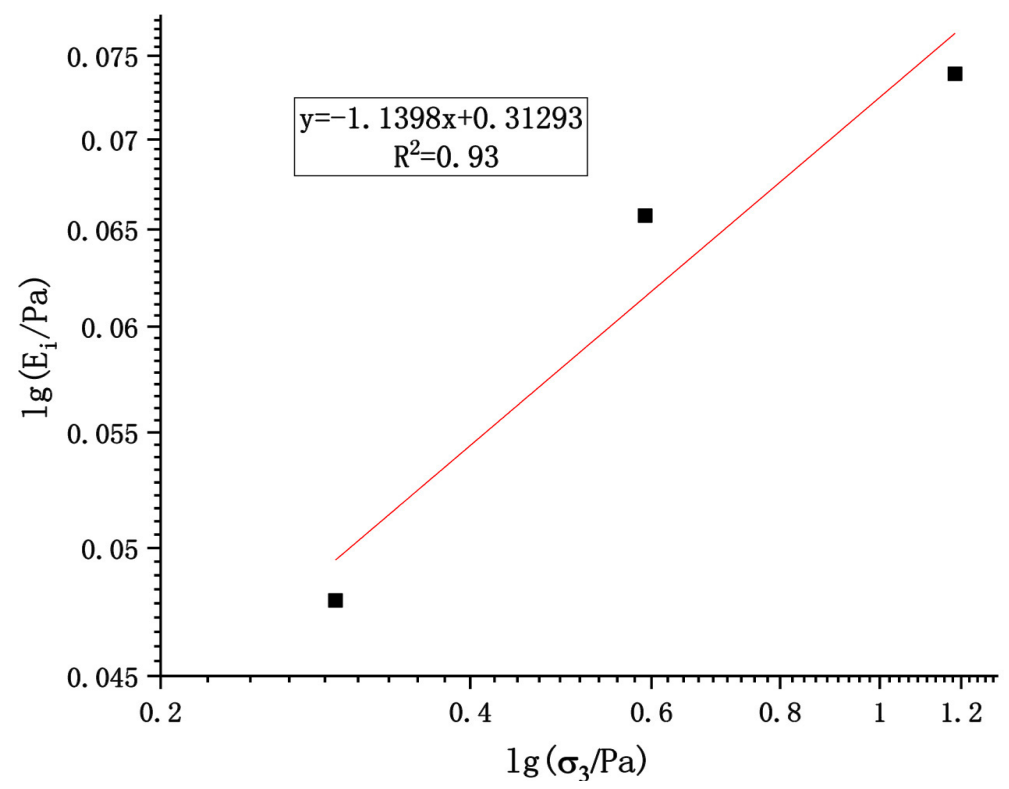

Figure 4. $\lg \left(\sigma_{3} / P_{a}\right) \sim \lg \left(E_{i} / P_{a}\right)$ relation curve.

Table 2. Duncan-Chang model parameter summary.

\begin{tabular}{cccccc}
\hline Test group & $C_{\text {ии }}(\mathrm{kPa})$ & $\varphi_{\text {uи }}\left({ }^{\circ}\right)$ & $R_{f}$ & $K$ & $n$ \\
\hline 1 & 20.18 & 0 & 0.756 & 0.389 & 1.198 \\
2 & 17.07 & 0 & 0.768 & 0.317 & 0.633 \\
3 & 8.85 & 0 & 0.795 & 0.072 & 0.313 \\
4 & 3.72 & 0 & 0.716 & 0.022 & 0.255 \\
5 & 4.28 & 0 & 0.861 & 0.043 & 0.150 \\
6 & 3.78 & 0 & 0.679 & 0.047 & 0.531 \\
7 & 14.87 & 0 & 0.740 & 0.344 & 0.799 \\
8 & 13.41 & 0 & 0.872 & 0.517 & 0.552 \\
Range & $3.72-20.18$ & 0 & $0.679-0.872$ & $0.022-0.517$ & $0.150-1.198$ \\
\hline
\end{tabular}




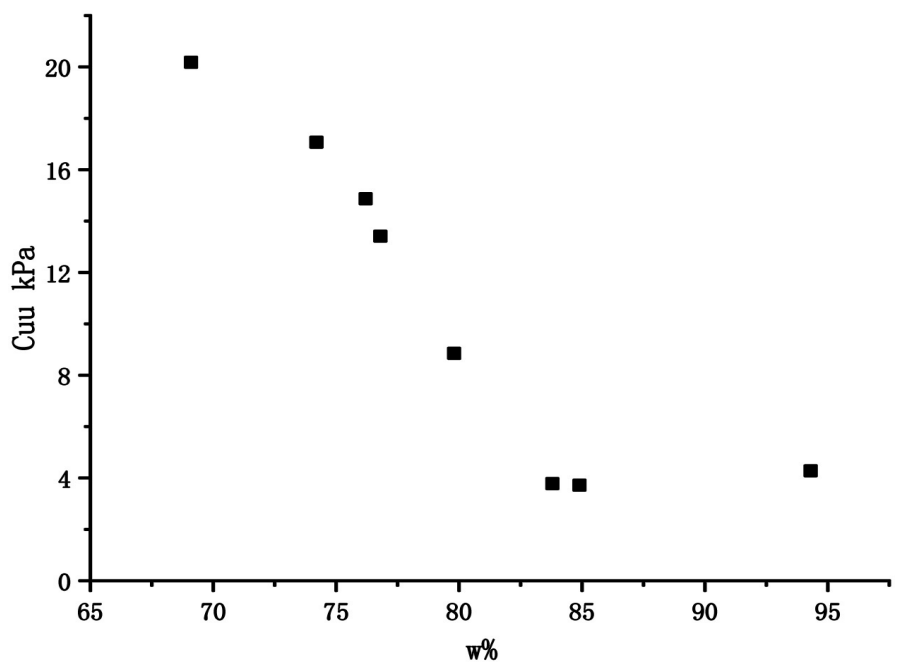

Figure 5. $C_{u u} \sim w$ relation cloud diagram.

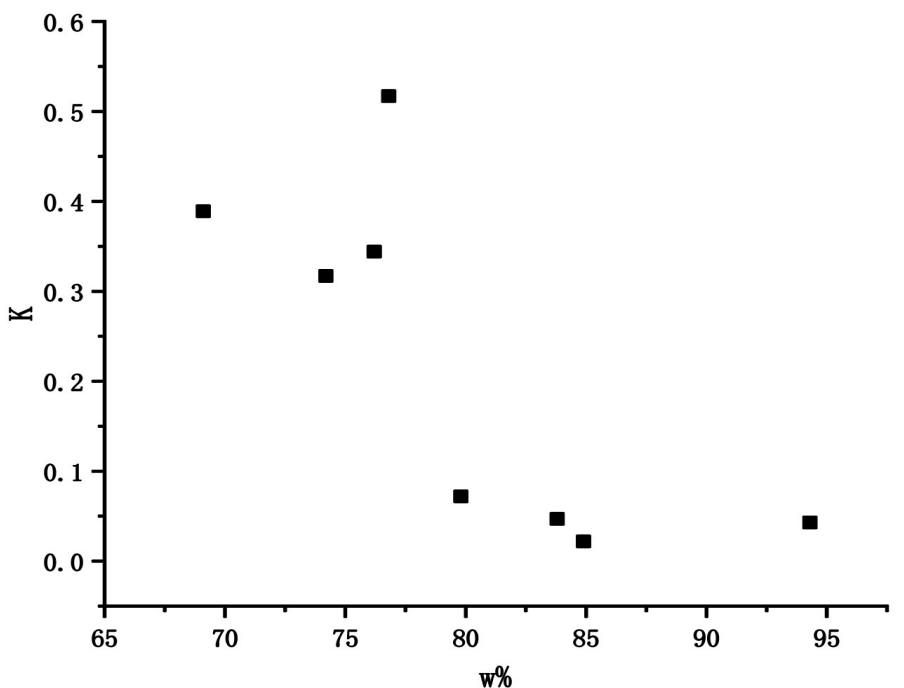

Figure 6. $K \sim w$ relation cloud diagram.

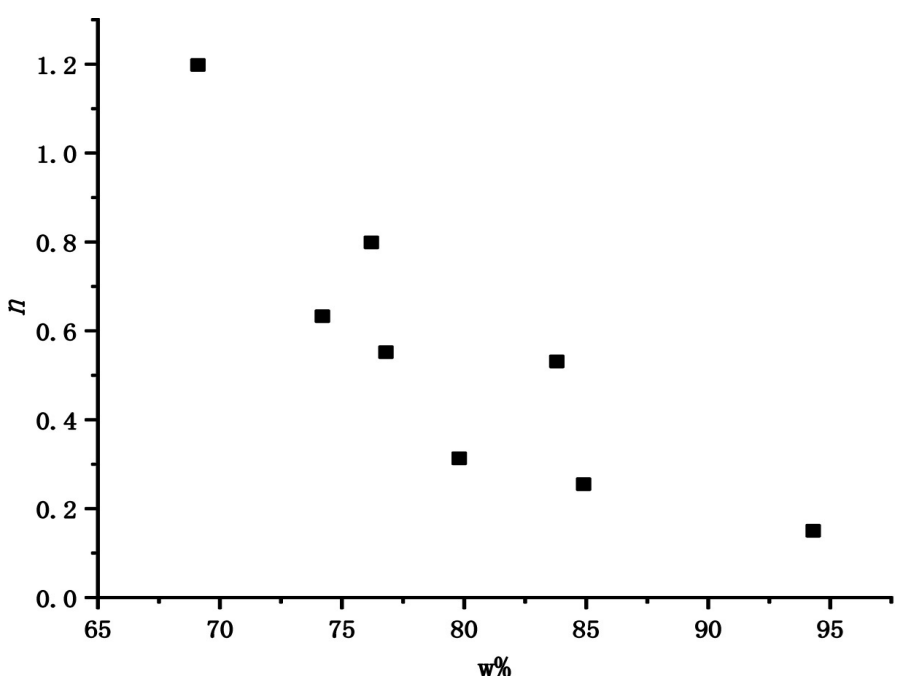

Figure 7. $n \sim w$ relation cloud diagram. 


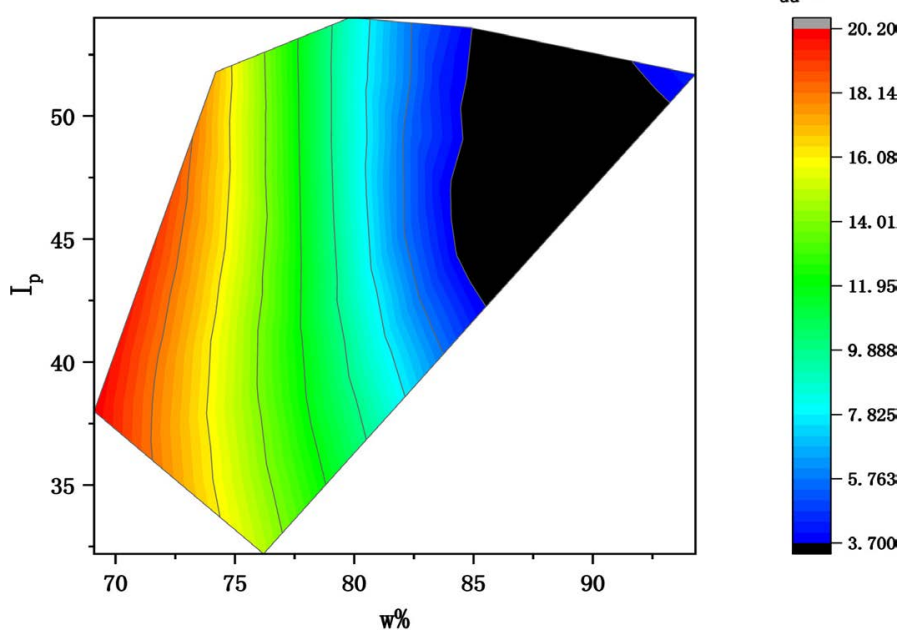

Figure 8. $C_{u u} \sim\left(w, I_{p}\right)$ relation cloud diagram.

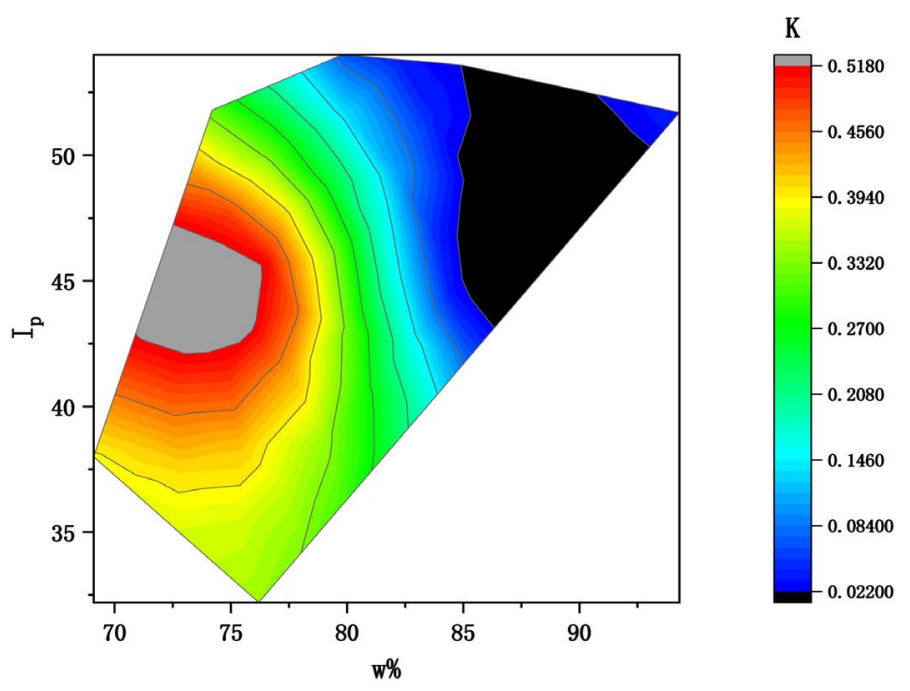

Figure 9. $K \sim\left(w, I_{p}\right)$ relation cloud diagram.

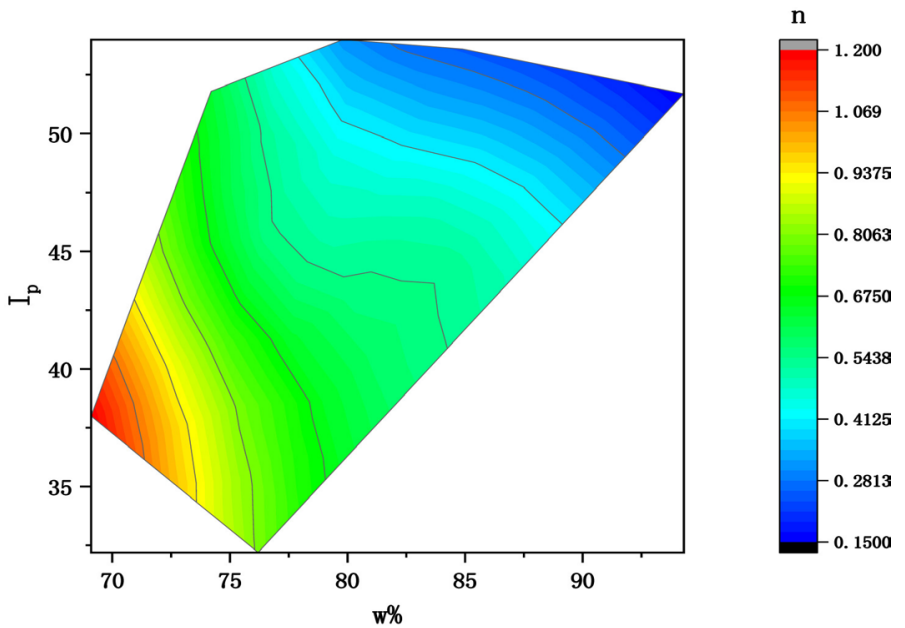

Figure 10. $n \sim\left(w, I_{p}\right)$ relation cloud diagram. 
The maximum value of $C_{u u}$ is $20.18 \mathrm{kPa}$ when the moisture content is $69.1 \%$ and the plasticity index is 38.0 . The minimum value of $C_{u u}$ is $3.72 \mathrm{kPa}$ when the moisture content is $84.9 \%$ and the plasticity index is 53.6 . The maximum to minimum ratio is 5.42 .

Figure 9 shows that when moisture content is constant, $K$ increases with the increase of plasticity index within the range of $70 \%-80 \%$ moisture content, and changes little with the increase of plasticity index when moisture content is greater than $80 \%$. When the plasticity index is constant, $K$ decreases with the increase of moisture content. The maximum value of $K$ is 0.517 when the moisture content is $76.8 \%$ and the plasticity index is 45.1 . The minimum value of $K$ was 0.022 when the moisture content was $84.9 \%$ and the plasticity index was 53.6. The maximum to minimum ratio is 23.5 .

Figure 10 shows that when the moisture content is constant, $\mathrm{n}$ changes little. When the plasticity index is constant, $\mathrm{n}$ decreases with the increase of moisture content. The maximum value of $n$ is 1.198 when the moisture content is $69.1 \%$ and the plasticity index is 38.0. The minimum value of $n$ was 0.150 when the moisture content was $94.3 \%$ and the plasticity index was 51.7 . The maximum to minimum ratio is 7.99 .

\section{Conclusions}

Through the triaxial unconsolidated undrained shear test of 8 groups of soft soil with moisture content of $69.1 \%-94.3 \%$ and plasticity index of $32.2-54.1$, the relationship between the four material parameters $K, n, C$ and $R_{f}$ of tangential deformation modulus of Duncan-Chang model and the moisture content and plasticity index of soil samples are analyzed, and the conclusions are as follows:

1) With the increase of moisture content, $C_{u u}, K$ and $n$ values all showed a downward trend, and $R_{f}$ variation was not obvious. With the increase of plasticity index, the variation rule of each parameter is not obvious.

2) When water content is constant, $C_{u u}$ and $n$ values do not change much. $K$ increases with the increase of plasticity index within the range of $70 \%-80 \%$ moisture content, and changes little with the increase of plasticity index when the moisture content is greater than $80 \%, R_{f}$ has no obvious rule. When the plasticity index is constant, $C_{u u}, K$ and $n$ decrease with the increase of moisture content, $R_{f}$ has no obvious rule.

3) The test constant $K$, whose maximum value is 23.5 times of the minimum value, is most significantly affected by moisture content and plasticity index. The influence is relatively small for $C_{u u}$ and test constant $n$, the difference between the maximum and minimum values is 5.42 and 7.99 times respectively. The smallest influence is $R_{f}$ whose maximum value is only 1.28 times different from the minimum value.

\section{Conflicts of Interest}

The authors declare no conflicts of interest regarding the publication of this paper. 


\section{References}

[1] Liu, X. and Chen, X. (2012) A Triaxial Test Study on the Strength of Remolded Laterite. Journal of Nanchang University (Engineering and Technology Edition), 34, 239-242.

[2] Chen, W., Zhang, W. and Ma, Y. (2014) Triaxial Test of Compacted Loess Strength. China Earthquake Engineering Journal, 36, 239-242.

[3] Liao, H., Li, T. and Peng, J. (2011) Study on the Strength Characteristics of Loess of High and Steep Slope. Rock and Soil Mechanics, 32, 1939-1944.

[4] We, N., Lai, R. and Zou, W. (2013) Effect of Water Content on Duncan-Chang Model Parameters of Granite Residual Soil. Journal of Wuhan Institute of Technology, 35, 18-23.

[5] Yang, X. (2008) Experimental Study on Strength Characteristics of Unsaturated Remolded Loess. Northwest A\&F University, Yanglin.

[6] Zdravkovic, L. and Jardine, R.J. (2001) The Effect on Anisotropy of Rocating the Principal Stress Axes during Consolidation. Geotechnique, 51, 69-83.

https://doi.org/10.1680/geot.51.1.69.39359

[7] Cokca, E., Erol, O. and Armangi, F. (2004) Effects of Compaction Moisture Content on the Shear Strength of an Unsaturated Clay. Geotechnical and Geological Engineering, 22, 285-297. https://doi.org/10.1023/B:GEGE.0000018349.40866.3e

[8] Cheng, Y., Li, L. and Chen, H. (2011) Effects of Dry Density on Duncan-Chang Model Parameters of Marine and Fluvial Soft Soils. Highway Engineering, 36, 61-76.

[9] Wang, S. (2016) Experimental Study on Strength Variation and Constitutive Model during Soft Soil Reinforcement. Tianjin University, Tianjin. 